\title{
The Development of Professionals for Research Management in Malaysia
}

\author{
Hsiao Wei $\operatorname{Tan}^{1, *}$
}

\section{${ }^{*}$ Corresponding author email: tanhw@um.edu.my}

Received date: 28 Feb 2020

Published date: 31 Dec 2020

\section{How to cite:}

Tan, H.W. (2020). The Development of Professionals for Research Management in Malaysia. Journal of Research Management \& Governance, 3(1), 36-41. Retrieved from https:// ejournal.um.edu.my/index.php/ JRMG/article/view/22438

DOI:

https://doi.org/10.22452/

jrmg.vol3no1.3

\begin{abstract}
Research activities in Malaysian universities have increased dramatically since the year 2007. Since then, the role of the research management office has evolved due to the increasing demand internally and externally. Traditionally, academics are seconded to manage research at local universities. In view of the growing complexity and volume of tasks and responsibilities in managing research, the development of the research management profession is critically needed. However, the profession was only the initiative of individual universities and wasn't formally recognised at the national level. The turning point of this situation happened in 2015, where there was support from the Ministry when a two-phase project related to the enhancement of research management was initiated at the national level. The project studied the strengths and weaknesses of current research management practices in Malaysian public universities and the drafting of strategies and action plans for implementation. One of the recommendations from the Malaysian Research Management \& Governance Project (MRMG) project was to develop a network for research managers and administrators in Malaysia so that this group of professionals can improve and learn from their peers via the sharing of best practices and exchange ideas. The first association of the profession was established in 2019 after three hardworking years since the Phase I concluded. The establishment of the association indicated that the acceptability of the profession into the academic communities and universities.
\end{abstract}

Keywords: Manager; Administrator; Profession; Newton Fund; Association

\section{Introduction}

Research management is an emerging field in Malaysian institutions and universities. The establishment of research support offices at the Malaysian institutions and universities started when the Malaysian Government increased its R\&D budget since the 7th Malaysia Plan (RMK-7) in 1996.

Research activities within the Malaysian institutions and universities have been increased dramatically over time. This was reflected in the research performance of the Malaysian institutions and universities. As shown in Figure 1, the total number of Web-of-Science (WoS) publications published by the Malaysian universities has increased exponentially. The increment was mainly attributed to the Malaysian Government's aspiration to create a knowledge-based economy (Nasiibah, 2013). The 
Government has allocated resources to the local universities to boost the research and innovation activities in Malaysia.

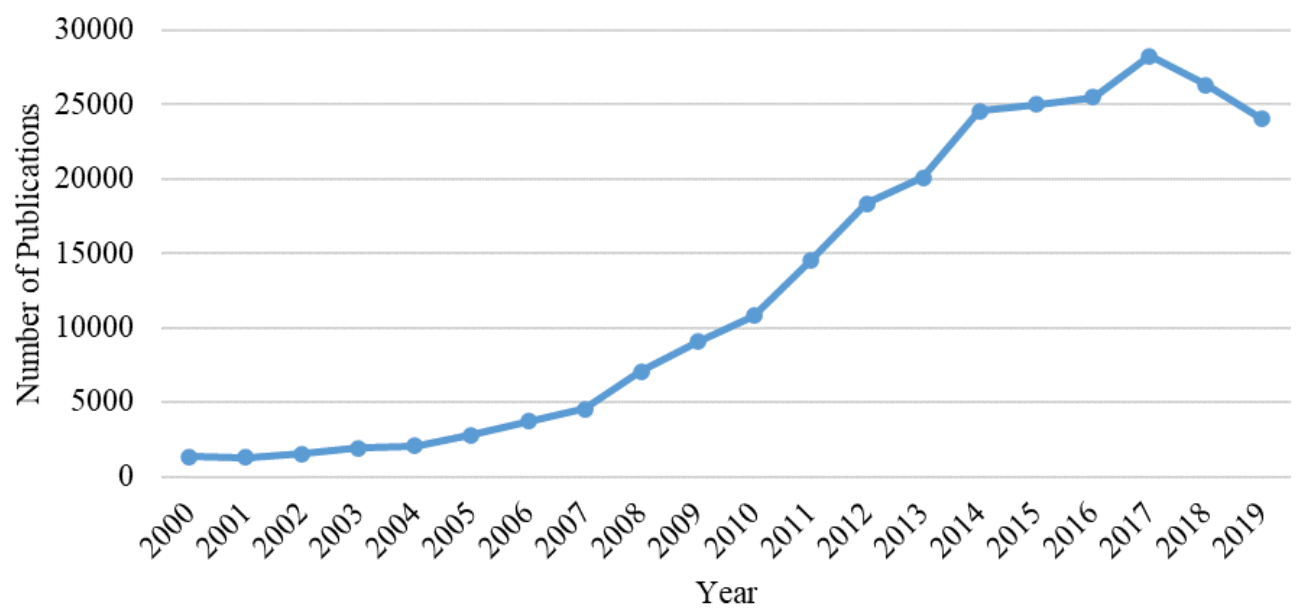

Figure 1: Total number of Web-of-Science (WoS) indexed publications published by Malaysian researchers since the year of 2000 (data collected as of July 2020).

Delivery of a large number of research activities successfully requires hard work by not only brilliant researchers but also excellent administrators who can provide outstanding services and supports. For this reason, the role of the research offices has evolved and become more complex to manage the challenging tasks efficiently. The type of services offered to support research has expanded, from the administration of research grants to management of research. However, the development of the research management profession did not receive much attention in Malaysia. This article discusses the traditional practice in managing research and its evolution within Malaysian universities.

\section{Progression in Research Management}

Traditionally, the management of research has always been the responsibility of academics and supported by supporting staff (non-academics) for clerical work. Academics are seconded to the university research office to carry out research management such as research grant management, institutional reporting, and stakeholder engagement, which include the communities and industries. There was a strong belief that academics are in touch with research and able to understand the complexities in carrying out research. Therefore, academics would be able to facilitate researchers better from first-hand experience. These academics are often excellent performers in teaching, supervising, and conducting research. However, the secondment of these excellent academics to administrative jobs on research management can cause a loss to the university.

As the emphasis of the knowledge-based economy in Malaysia were intensified since RMK-7, the country's had recorded a growth (Figure 2) in the gross expenditure in research development (GERD) as a percentage of gross domestic product (\% of GDP) (Academy of Science Malaysia, 2017; UNESCO, 2020). The GERD by higher education as a \% of GDP (Figure 3), on average, was always $20-30 \%$ of the 
Malaysia overall GERD as a \% of GDP from 2008. This data has further confirmed and reflected the volume of research activities carried out at the Malaysian Universities.

The increase in R\&D investment at the universities also came with increasing funding agencies' requirements, especially in monitoring and reporting the funding's output, outcome, and impact. The massive amount of work to fulfill the increased requirements were loaded on the academics who were tasked to manage research. This has been a challenge because it affects not only the performance and quality of work of the said academics but also the university. The universities' management started to explore and search for potential solutions to overcome the challenge.

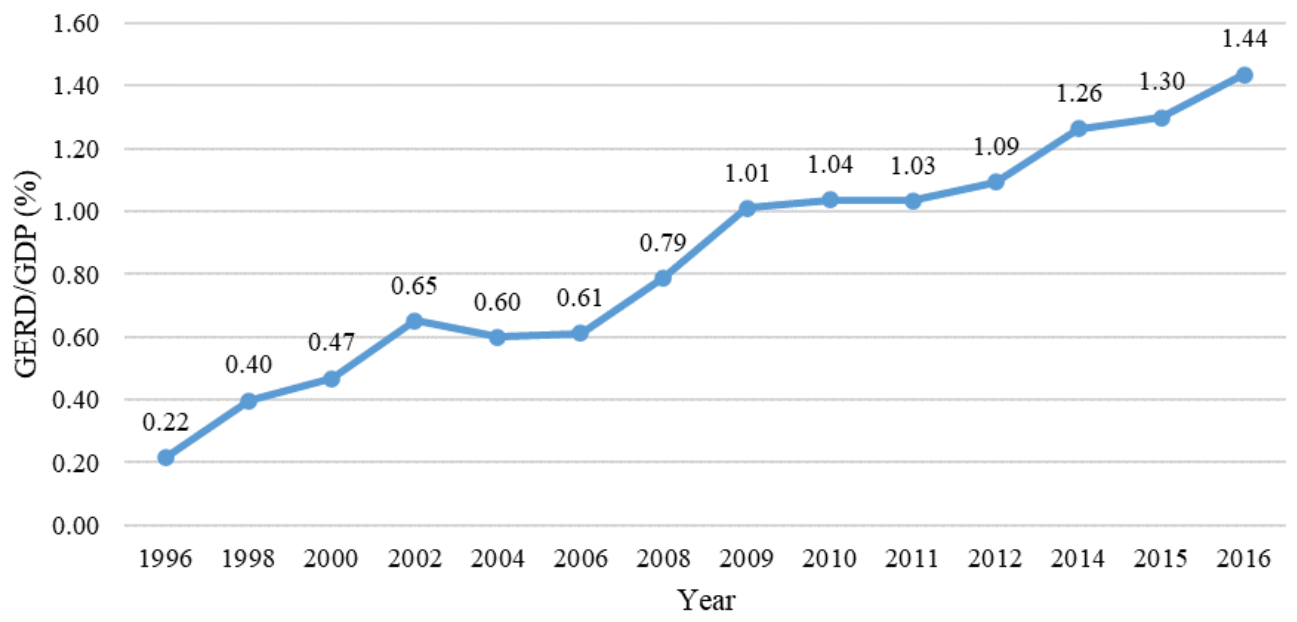

Figure 2: The Malaysia GERD as \% of GDP from 1996-2016 (UNESCO, 2020).

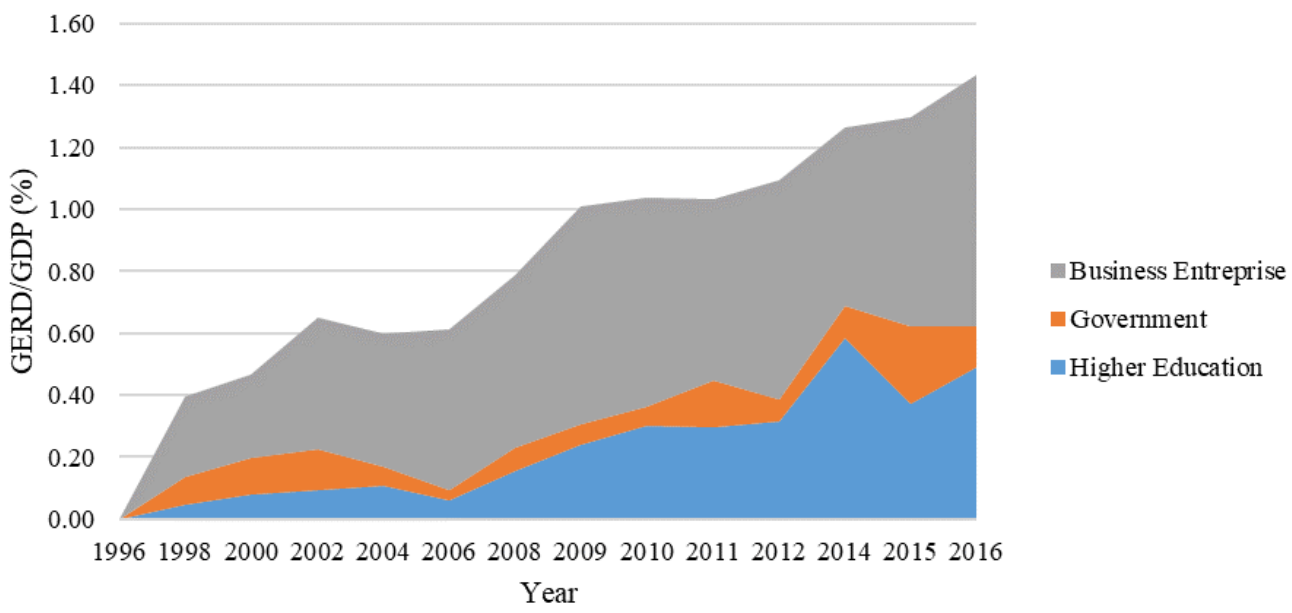

Figure 3: The Malaysia GERD by sector as \% of GDP from 1996-2016 (UNESCO, 2020). 
The concept of professionals for research management only came into the picture when the leaders of Malaysian universities attended research management conferences and forums. This concept was then slowly introduced into the Malaysian university research management structure, including the appointment of personnel with the related background to manage research fulltime. The recruits in research management include Ph.D. holders who are passionate about managing research. This move has addressed the concern in understanding the complexity of research work. However, it has been the initiative of individual universities without official recognition of the profession.

Today, there is support from the Ministry when projects related to the enhancement of research management were initiated at the national level. The first national project on research management entitled Malaysian Research Management \& Governance Project (MRMG) started in 2015 and it was funded by the Newton-Ungku Omar Fund (NUOF) for Professional Development and Engagement. This project was conducted in two phases, 2015-2016 and 2016-2019. As the project owner, the Institutions of Higher Learning Excellence Planning Division (BPKI), which was then the Institutions of Higher Learning Research Excellence Division (BKPI) under the Ministry of Higher Education, had invited Universiti Malaya to participate and act as the project implementer to manage and deliver the project output.

Phase I of the MRMG project studied the strengths and weaknesses of current research management practices in Malaysian public universities, and Phase II prepared and drew the implementation strategies and action plans. Surveys were carried out to collect feedback from the academics, research administrators, and university management, regarding the research management practices at respective universities. The project concluded with several suggestions and areas for improvement, including strategies and plans for implementation. The suggestions and recommendations mainly fell within four topics. The development of the research management profession in Malaysia was one of the identified topics.

Amongst the recommended topics, the development of a network for research managers and administrators in Malaysia was one of them. The network should act as a platform that could encourage and bring this group of professionals together, and improve their knowledge of the research ecosystem, professional skills, and personal skills via sharing of best practices and exchange of ideas. It was a wellknown fact that managing research adopts the on-the-job training method. Managing research is not a traditional subject that can be taught at the school due to the nature of work and changing needs from the stakeholders such as the funding agencies, the Government, etc. The scope of work can vary from developing proposals to the management of ethics, strategies, and policies. Therefore, knowledge and specific skills in managing research were often gained and developed via the sharing of experiences, best practices, and solving the challenges that occur during the performance of the tasks. As compared to the countries with a long history of research management, there are still gaps to be filled in the Malaysian research management such as official recognition of the profession, career development, support structure, training, certification, etc. 


\section{The Profession and Association}

On the 31 July 2019, the very first association, The Malaysia Association of Research Managers and Administrators (MyRMA), was officially established by a group of passionate researchers and research managers with a vision to pursue excellence in research management towards realizing impactful research. A launching ceremony of the MyRMA was held on 22 September 2019. It was launched by Y.Bhg. Datuk Ir. Dr. Siti Hamisah Tapsir, the Director-General Higher Education, Ministry of Education Malaysia. MyRMA shall be the catalyst to ensure Malaysia's research management heading in the right direction and in being on par with international players (Tan, 2019).

MyRMA aims to (i) facilitate impactful research by identifying and establishing best practices in research management and administration, and (ii) nurture excellence in the research management profession. It creates a platform for research managers and administrators from the public, private, academic, and research agencies, as well as donors, to interact, exchange ideas, sharing best practices and conduct collaborative activities (Figure 4). It is expected to contribute towards enhancing the effectiveness of research management, the quality of the research itself, and improvement in the return-on-investment.

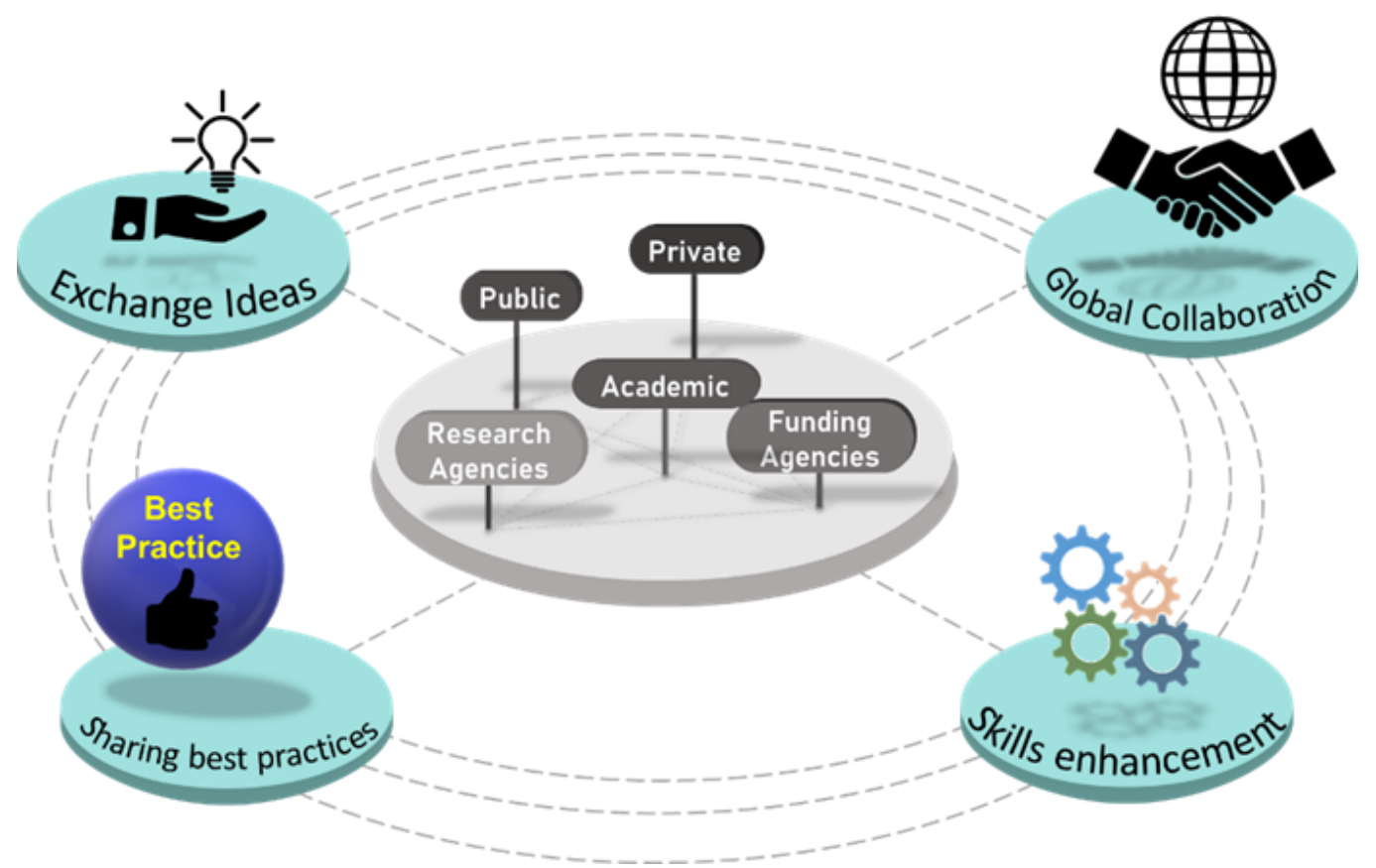

Figure 4: The Malaysia GERD as \% of GDP from 1996-2016 (UNESCO, 2020).

\section{Conclusion}

As Malaysian research management progresses towards professionalism in research management, networking and benchmarking with international research management associations are important. Learning from the experts and working closely with them is crucial and would help in developing the skills for the Malaysian research managers and administrators. 
The establishment of MyRMA provides an opportune time for all of the stakeholders in the country to make the first step towards the sharing and exchanging of knowledge, ideas, and experiences in research management. This can propel the country into a knowledge-driven society, and impulse the Malaysian research management to the next level.

\section{Acknowledgement}

I would like to extend my gratitude to the Newton-Ungku Omar Fund, Professional Development and

Engagement Programme, British Council, and the Malaysian Industry-Government Group for High Technology (MiGHT) for sponsoring the MRMG project phase I and phase II (IF020-2015 and IF0182016).

\section{References:}

Academy of Sciences Malaysia. (2017). Science Outlook. Malaysia: Academy of Sciences Malaysia.

Nasiibah, R., Zinatul, A.Z., Junaidi, A.A., Hasani, M.A., Jady, H., Wan M.H.W.H., Ruzian, M., Wan, S.A.W.D. \& Noor, I.Y. (2013). The Concept of Research University: The Implementation in the context of Malaysian University System. Asian Social Science, 9, 307-317.

Tan, H.W. (2019). Establishment of the Malaysia Association of Research Managers and Administrators (MyRMA).Milestone@uM Newsletter, 7(3), 4-5.

UNESCO Institute For Statistics. (2020). Science, technology and innovation: Gross domestic expenditure on R\&D (GERD), GERD as a percentage of GDP, GERD per capita and GERD per researcher [Data file]. Retrieved from http://data.uis.unesco.org/index.aspx?queryid=74\#. 